\title{
An intensive study on pesticides contamination and its removal in fruits and vegetables collected from Ghaziabad, India
}

\author{
Astha Bhatnagar ${ }^{1}$, Richa Dave ${ }^{1 *}$, Tanu Jindal ${ }^{2}$, J.S Virdi ${ }^{3}$ \\ ${ }^{1}$ Amity Institute of Environmental Sciences, Amity University Uttar Pradesh, Sector-125, Noida, U.P. -201303, India \\ ${ }^{2}$ Amity Institute of Environmental Toxicology, Safety and Management, Amity University Uttar Pradesh, Sector-125, Noida-201303, India \\ ${ }^{3}$ Department of Microbiology, University of Delhi, South Campus, New Delhi-110021, India \\ Received - November 22, 2021; Revision - January 26, 2022; Accepted - February 20, 2022 \\ Available Online - February 28, 2022
}

DOI: http://dx.doi.org/10.18006/2022.10(1).104.116

\section{KEYWORDS}

Pesticide residue

Fruits and vegetables

QUECHERS extraction

Translocation

DMRT

Washing solution

\begin{abstract}
These days pesticides are extensively applied in agriculture to increase productivity; although these pesticides increase productivity but also have a negative impact on the consumer. Thus, pesticide exposure in agricultural products must be decreased. The present study attempted to assess pesticide residues in samples of apple, tomato, and brinjal and determine the efficacy of washing solutions in pesticide removal. For sample preparation, the QuEChERS method was employed, and prepared samples were analyzed using gas chromatography-mass spectrometry. Results of the study revealed that among the collected samples, 58.33 percent samples were showing lower pesticide residues as compared to the maximum residue limit (MRL) while 12.5 percent of the samples were showing higher pesticides residues as compared to the suggested MRL. Further, from the collected fruits and vegetable samples, the presence of the chlorantraniliprole, carbendazim, beta endosulfan, chlorpyrifos, malathion, carbaryl, thiomethoxam, DDT, and flubendiamide were detected in the range of $0.0-1.41 \mathrm{mg} / \mathrm{kg}$. Among the detected pesticides, chlorpyrifos and flubendiamide were the most commonly detected pesticides. Effectiveness of different washing solutions was studied, which indicated a significant reduction in residues of all the washing solutions compared with the control $(\mathrm{p}<0.05)$ and concluded that ascorbic acid and sodium bicarbonate solution was very effective in pesticides removal compared with water and chemical alone.
\end{abstract}

* Corresponding author

E-mail: richadave11@gmail.com (Dr. Richa Dave)

Peer review under responsibility of Journal of Experimental Biology and Agricultural Sciences.

Production and Hosting by Horizon Publisher India [HPI] (http://www.horizonpublisherindia.in/).

All rights reserved.
All the articles published by Journal of Experimental Biology and Agricultural Sciences are licensed under a Creative Commons Attribution-NonCommercial 4.0 International License Based on a work at www.jebas.org.

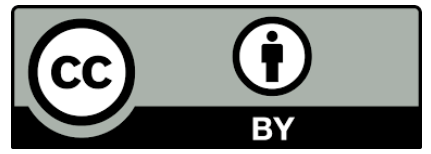




\section{Introduction}

Pesticides are extensively used in worldwide agriculture to control pests. The use of pesticides helps in increasing crop yield, protecting crops from insects and pests, and extending their storage life. Pesticides are often used in developing countries to boost food production (Omwenga et al. 2021; Akoto et al. 2015). Although excessive use of pesticides increases agricultural production, on the other hand, excessive use of pesticides has negative health consequences. The acute neurotoxic insecticides, namely organophosphates (OPs), carbamates (CBs), and pyrethroids (PYs), have different modes of action in humans and other mammals, are among the several pesticide categories to which humans are exposed through their diet (Jardim et al. 2018). Health risks of pesticides range from headaches and nausea to long-term effects such as cancer, congenital disorder, dysgenesis, and endocrine disruption (Jallow et al. 2017). The levels of organochlorine pesticides (OCP) are elevated in patients with colorectal cancer (Abolhassani et al 2019). Most of the applied pesticides may exist in the environment as residues. Pesticide residues are the remains of an active component, metabolite, or byproduct of a pesticide. Further, some pesticides are persistent, and they accumulate in the environment. Accumulation of pesticides in the soil, water, and from here to different plant parts is the most common route through which these pesticides enter into the food chain and are showing biomagnification (Kaushik et al. 2009). Biomedical studies from US and Canada have demonstrated pesticide residues in biological fluids (Omwenga et al. 2021; Haines et al. 2017; Centers for disease control and prevention 2019).

Insecticides, fungicides, and herbicides are commonly used for controlling pests, and these products exhibit high pesticide levels (Nguyen et al. 2020). According to the ICAR-National Institute of Agriculture Economics and Policy Research report, the annual pesticide consumption in India was approximately $0.29 \mathrm{~kg} / \mathrm{hectare}$ per year in 2016-17 (Subash et al. 2018). Pesticide consumption is highest in Maharashtra, followed by Uttar Pradesh, Punjab, and Haryana (Subash et al. 2018). Due to a lack of knowledge, farmers tend to apply pesticides near the harvest period just before reaching the end-user in the market. Thus, to ensure the safety of consumers, countries around the world have set up the maximum residual limit (MRL). In India, "The Food Safety and Standard Authority of India" under the Ministry of Health and Family welfare utilizes the Good Agricultural Practice data for MRL fixation (FSSAI Guidance Note. 13/2020). The MRL is calculated based on the estimated food consumption for each crop is less than $80 \%$ of the permissible daily intake and a risk assessment. Estimated food intake is calculated by multiplying the MRL by food. Thus, food commodities contaminated with pesticides must be monitored, whereas actions to remove pesticides from the food crops are vital for food safety.
After China, India is the world's second-largest producer of fruits and vegetables. Fruits and vegetables consist of nutrients that are necessary for the human body to grow and heal itself. Fan et al. (2015) reported that the amount of pesticides used in vegetable crops is three times higher than those used for cereal crops. The most common fruits and vegetables that can be consumed directly and are affected by high pesticide residues are apples and tomatoes respectively. Washing and peeling are the most commonly used procedures for removing pesticide residues. Rinsing with water alone is not effective. Several studies have been investigated the efficacy of washing solutions in removing pesticide residues. The use of a $10 \%$ acetic acid solution to remove organochlorine and organophosphorus pesticides has been reported to be effective by Abou Arab (1999). Krol et al. (2000) reported the efficacy of brief rinsing with water. Polat \& Tiryaki (2020) confirmed that acetic acid and citric acid washing treatments are more efficient than tap water. Additionally, Rasolonjatovo et al. (2017) concluded that a blend of washing solutions is more effective than a single solution in removing pesticide residues. Although solvents used for pesticide removal can remove the residues, they cause toxic effects. Thus, the use of non-toxic washing solutions, which are easily available at home or can be easily prepared at home, has been attempted. The present study monitored the pesticide residues in fruits and vegetables to determine and mitigate the risks to human health, understand their translocation, and identify an effective washing solution for the removal of pesticides from the surface of fruits and vegetables.

\section{Materials and methods}

\subsection{Raw materials}

Raw apple, tomato, and brinjal samples (5-6 kg) were collected twice from the four different locations of Ghaziabad, Uttar Pradesh, India local market within 30 days during January 2019. Samples were refrigerated and analyzed within 1 week (Satpathy et al. 2012).

\subsection{Extraction of pesticide residues}

$5.0 \mathrm{~g}$ of homogenized sample was extracted with acetonitrile followed by the addition of magnesium sulfate, sodium chloride, trisodium citrate dihydrate, and potassium hydrogen citrate sesquihydrate. The extract clean-up was done using primary secondary amines and magnesium sulfate followed by evaporation of extract under a nitrogen evaporator at $35^{\circ} \mathrm{C}$. Final reconstitution was done with ethyl acetate and injected into the gas chromatography-mass spectrometry (GC-MS)/MS as suggested BS EN 15662:2018. 


\subsection{Instrument conditions}

The experimental setup was as per the Jallow et al. (2017) descriptions. The sample was injected in splitless mode on GCMS/MS with Autosampler (7000B, triple quadruple with Mass hunter software) having capillary column (HP-5MS; $30 \mathrm{~m} \times 0.25$ $\mathrm{mm} \times 0.25 \mu \mathrm{m})$. The column flow rate was $1.0 \mathrm{~mL} / \mathrm{min}$, and the initial column temperature was $60^{\circ} \mathrm{C}$. The injector temperature was set at $300^{\circ} \mathrm{C}$. The column oven ramping was set at an initial temperature of $60^{\circ} \mathrm{C}$, with a 1.0 minute hold time. The temperature was raised at the rate of $40.0^{\circ} \mathrm{C}$ per min to $170^{\circ} \mathrm{C}$ with no hold time and at the rate of $10.0^{\circ} \mathrm{C}$ to $310^{\circ} \mathrm{C}$ within $3.0 \mathrm{~min}$ (Tables 1 and 2).

Table 1 Chromatographic conditions for GC-MS/MS Column HP-5MS, $30 \mathrm{~m} \times 0.25 \mathrm{~mm} \times 0.25 \mu \mathrm{m}$

\begin{tabular}{|cc|}
\hline Column oven & $60^{\circ} \mathrm{C}$ \\
\hline Injector temperature & $300^{\circ} \mathrm{C}$ \\
\hline Injection Mode & Split less \\
\hline Carrier gas & Helium \\
\hline Flow rate & $1.0 \mathrm{~mL} / \mathrm{min}$ \\
\hline Injection volume & $1.0 \mu \mathrm{L}$ \\
\hline Run time & $22.75 \mathrm{~min}$ \\
\hline Mode & $\mathrm{MRM}$ \\
\hline Source temperature & $220^{\circ} \mathrm{C}$ \\
\hline Interface Temperature & $310^{\circ} \mathrm{C}$ \\
\hline Solvent delay & $3.00 \mathrm{~min}$ \\
\hline
\end{tabular}

\begin{tabular}{|cccc|}
\hline $\begin{array}{c}\text { Rate } \\
\left({ }^{\circ} \mathrm{C} / \mathrm{min}\right)\end{array}$ & $\begin{array}{c}\text { Final temp } \\
\left({ }^{\circ} \mathrm{C}\right)\end{array}$ & $\begin{array}{c}\text { Hold time } \\
(\mathrm{min})\end{array}$ & $\begin{array}{c}\text { Run time } \\
(\mathrm{min})\end{array}$ \\
\hline--- & 60 & 1.0 & 1 \\
\hline 40.0 & 170 & 0.0 & 3.75 \\
\hline 10.0 & 310 & 3.0 & 20.75 \\
\hline
\end{tabular}

\subsection{Translocation and pesticide removal in different washing solutions}

Pesticide mix solution of detected pesticides was prepared with an effective concentration of $100 \mathrm{ppm}$ in ethyl acetate. Pesticides mix was applied on the surface of the apple, tomato, and brinjal samples. A total of $50 \mu \mathrm{L}$ of pesticide mix stock (100 ppm) was applied and kept for $24 \mathrm{~h}$ at room temperature for pesticide deposition.

To study translocation, six spiked apple peel and pulp samples were analyzed along with surface pesticides by treating the surface with ethyl acetate after $24 \mathrm{~h}$ of spiking. Surface pesticides and peel were analyzed for tomatoes and brinjals, too.

To compare the translocation characteristics of pesticides in fruits and vegetables, the translocation factor (TF) was calculated using the following equations (Klinhom et al. 2008; Felizeter et al. 2012; Wang et al. 2019).

$$
\begin{gathered}
\text { TF for surface to peel }=\mathrm{C}_{\text {peel }} / \mathrm{C}_{\text {surface }} \\
\text { TF for peel to pulp }=\mathrm{C}_{\text {pulp }} / \mathrm{C}_{\text {peel }} \\
\text { TF for surface to pulp }=\mathrm{C}_{\text {pulp }} / \mathrm{C}_{\text {surface }}
\end{gathered}
$$

Here, $C_{\text {peel }}(\mathrm{mg} / \mathrm{kg}), \mathrm{C}_{\text {surface }}(\mathrm{mg} / \mathrm{kg})$, and $\mathrm{C}_{\text {pulp }}(\mathrm{mg} / \mathrm{kg})$ are the measured concentrations of a pesticide in the peels, surface, and pulp of fruits and vegetables, respectively.

To analyze washing solution effectiveness, one sample was analyzed to estimate the pesticide concentration in the control sample. Then, treatments with four different washing solutions, namely $0.1 \%$ ascorbic acid, $0.1 \mathrm{~N}$ sodium carbonate, ascorbic acid, and sodium bicarbonate mixture, and warm water, were administered. The treated samples were immersed in $200 \mathrm{~mL}$ of washing solution for $15 \mathrm{~min}$ with gentle agitation after every $5 \mathrm{~min}$ (Satpathy et al. 2012) and then rinsed with $200 \mathrm{~mL}$ tap water for $2 \mathrm{~s}$. After washing, fruit and vegetable samples were air-dried for $30 \mathrm{~min}$. The samples after washing were collected and extracted as per the extraction method and analyzed for pesticide residues.

\subsection{Statistical analysis}

All treatments were replicated thrice. The effects of washing solutions on percentage reduction of pesticides were determined using two-way analysis of variance, with the pesticides serving as main effects and the four washing solutions serving as minor effects. Significant differences between treatment effects and interactions were determined following a significant F-test $(\mathrm{P}<$ 0.05 ) by using all pair-wise comparisons of treatment means with DUNCAN's option (IBM SPSS) (Felizeter et al. 2012). A p-value of $<0.05$ was considered statistically significant.

\section{Results}

\subsection{Recovery study}

The method was validated through sensitivity/linearity, specificity, the limit of quantification (LOQ), matrix effect, recovery/ trueness, precision, within lab reproducibility, and robustness. Six blank samples were spiked at LOQ levels $(10 \mu \mathrm{g} / \mathrm{kg})$ quantified against the calibration curve. Mean recoveries of the standard thiabendazole, chlorantraniliprole, carbendazim, pp-DDT, lambda cyahalothrin, betaendosulfan, chlorpyrifos, permethrin, malathion, carbaryl, cyfluthrin, thiomethoxam, and flubendiamide added to 
the pesticide-free vegetables and fruits at $0.01 \mathrm{mg} / \mathrm{kg}$ were $97 \%$, $104.66 \%, 99.74 \%, 87 \%, 101 \%, 81 \%, 86 \%, 97.8 \%, 99.57 \%$, $106.91 \%, 84.78 \%, 99.98 \%, 96.11 \%$, and $105.42 \%$, respectively. LOQ recoveries were within the acceptance criteria of $70-120 \%$, with an associated relative standard deviation (RSD) of $\leq 20 \%$. The recovery percentage in the present study was higher than $80 \%$, indicating a validated analytical procedure. Further, the average recovery criteria as per SANTE/12682/2019 was 70-120\% at each level. RSD should be $<20 \%$ at each level. Based on the validation results, the present method was considered suitable for the estimation of pesticide residues in fruits and vegetables. The precision and accuracy were within the prescribed limits in the concentration range.

\subsection{Multiple residue detection in fruits and vegetables}

A total of 24 fruit and vegetable samples were used for pesticide residue analysis, and the ranges of detection levels are summarized in Table 3. Among the studied samples, 09 samples were free from residues. The pesticide residues in 14 samples were less than MRL and while in one sample it was reported higher than the recommended MRL value (Table 4). Further, among the apple samples, 9 (37\%) samples exhibited no residues, and 15 (63\%) samples had residues less than MRL. Among the studied tomato samples, $6(25 \%)$ samples exhibited no pesticides residues, 15 (62\%) samples exhibited residues less than MRL, and 3 (13\%) samples exhibited residues greater than the MRL recommendation. Among the brinjal samples, $12(50 \%)$ samples exhibited no residues, and 12 (50\%) samples exhibited residues less than MRL (Figure 1). A high percentage of contaminated samples were observed in tomatoes $(75 \%)$.

The most common pesticides observed in fruits and vegetables were carbendazim (15 samples), chlorpyrifos (12 samples), flubendiamide (15 samples), and chlorantaniliprolein (6 samples). Beta endosulfan, malathion, and carbaryl were observed in 3 apple samples; while thiomethoxam and DDT were observed in 6 and 3 tomato samples, respectively. In 3 tomato samples, chlorpyrifos exceeded its MRL. The residue content of fruits and vegetables is illustrated in Table 5 and Figure 2. In 37.5 percent of the samples, there was only one pesticide residue, whereas, in $29.1 \%$ of the samples, there were multiple pesticide residues.

Table 3 Pesticides level detected in selected fruits \& vegetables collected from Ghaziabad location

\begin{tabular}{|cccc|}
\hline Pesticides Name & $\begin{array}{c}\text { Pesticides detected in } \\
\text { Apple }(\mathrm{n}=8)\end{array}$ & $\begin{array}{c}\text { Pesticides detected in } \\
\text { Tomatoes }(\mathrm{n}=8)\end{array}$ & $\begin{array}{c}\text { Pesticides detected in } \\
\text { Brinjal (n=8) }\end{array}$ \\
\hline Thiabendazole, $\mathrm{mg} / \mathrm{kg}$ & $\mathrm{ND}$ & $\mathrm{ND}$ & ND \\
\hline Chlorantraniliprole, $\mathrm{mg} / \mathrm{kg}$ & $\mathrm{ND}$ & $\mathrm{ND}$ & ND \\
\hline Carbendazim $(\mathrm{MBC}), \mathrm{mg} / \mathrm{kg}$ & $0.0-0.023$ & ND \\
\hline Lambda Cyahalothrin, $\mathrm{mg} / \mathrm{kg}$ & $\mathrm{ND}$ & $\mathrm{ND}$ & ND \\
\hline BetaEndosulfan, $\mathrm{mg} / \mathrm{kg}$ & $0.0-0.035$ & $\mathrm{ND}$ & ND \\
\hline Chlorpyrifos, $\mathrm{mg} / \mathrm{kg}$ & $0.0-0.021$ & $0-0.21$ & $0.0-0.022$ \\
\hline Permethrin, $\mathrm{mg} / \mathrm{kg}$ & $\mathrm{ND}$ & $\mathrm{ND}$ & ND \\
\hline Malathion, $\mathrm{mg} / \mathrm{kg}$ & $0.0-0.018$ & $\mathrm{ND}$ & ND \\
\hline Carbaryl, $\mathrm{mg} / \mathrm{kg}$ & $0.0-0.035$ & $\mathrm{ND}$ & $0.0-0.025$ \\
\hline Cyfluthrin, $\mathrm{mg} / \mathrm{kg}$ & $\mathrm{ND}$ & $\mathrm{ND}$ & ND \\
\hline Thiomethoxam, $\mathrm{mg} / \mathrm{kg}$ & $\mathrm{ND}$ & $0-0.026$ & ND \\
\hline DDT, $\mathrm{mg} / \mathrm{kg}$ & $\mathrm{ND}$ & $0-0.032$ & $0.0-6.76$ \\
\hline Flubendiamide, $\mathrm{mg} / \mathrm{kg}$ & $\mathrm{ND}$ & $0.0-7.96$ & \\
\hline
\end{tabular}

Table 4 Pesticides Residues in analysed Samples

\begin{tabular}{|cccc|}
\hline Produce & $\begin{array}{c}\text { Without } \\
\text { Residue }\end{array}$ & $\begin{array}{c}\text { With Residue } \\
<\text { MRL }\end{array}$ & $\begin{array}{c}\text { With Residue } \\
>\text { MRL }\end{array}$ \\
\hline Apple & 3 & 5 & 0 \\
\hline Tomatoes & 2 & 5 & 1 \\
\hline Brinjal & 4 & 4 & 0 \\
\hline
\end{tabular}

Table 5 Co-occurrences of pesticides Residues in Samples \begin{tabular}{l|ll} 
Number of Residues & $\%$ of Samples $\quad$ No of Samples
\end{tabular}

\begin{tabular}{|ccc|}
\hline 0 residue & 33.3 & 8 \\
\hline 1 Residue & 37.5 & 9 \\
\hline 2 Residue & 20.8 & 5 \\
\hline >3 Residue & 8.3 & 2 \\
\hline
\end{tabular}



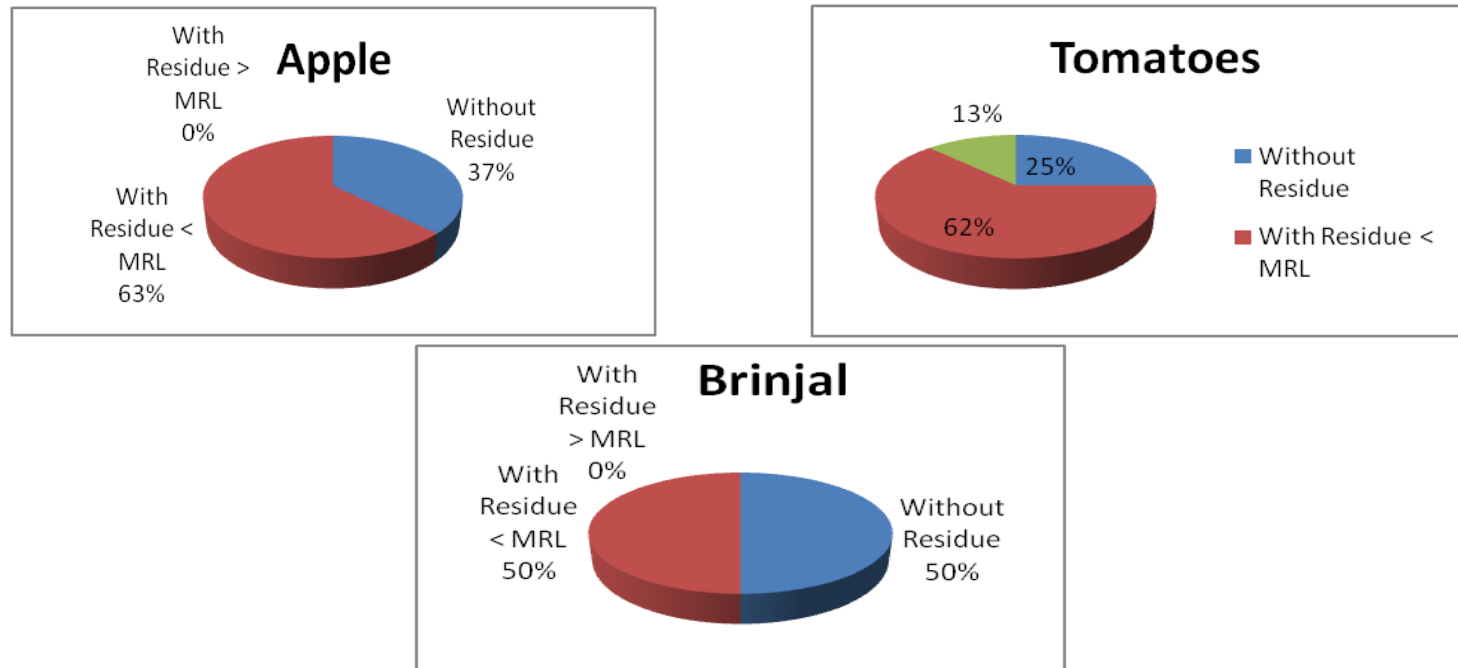

Figure 1 The detected pesticides frequency in whole, tomato and brinjal samples compared to maximum residual limits (MRL) along with frequency of MRL exceedance.

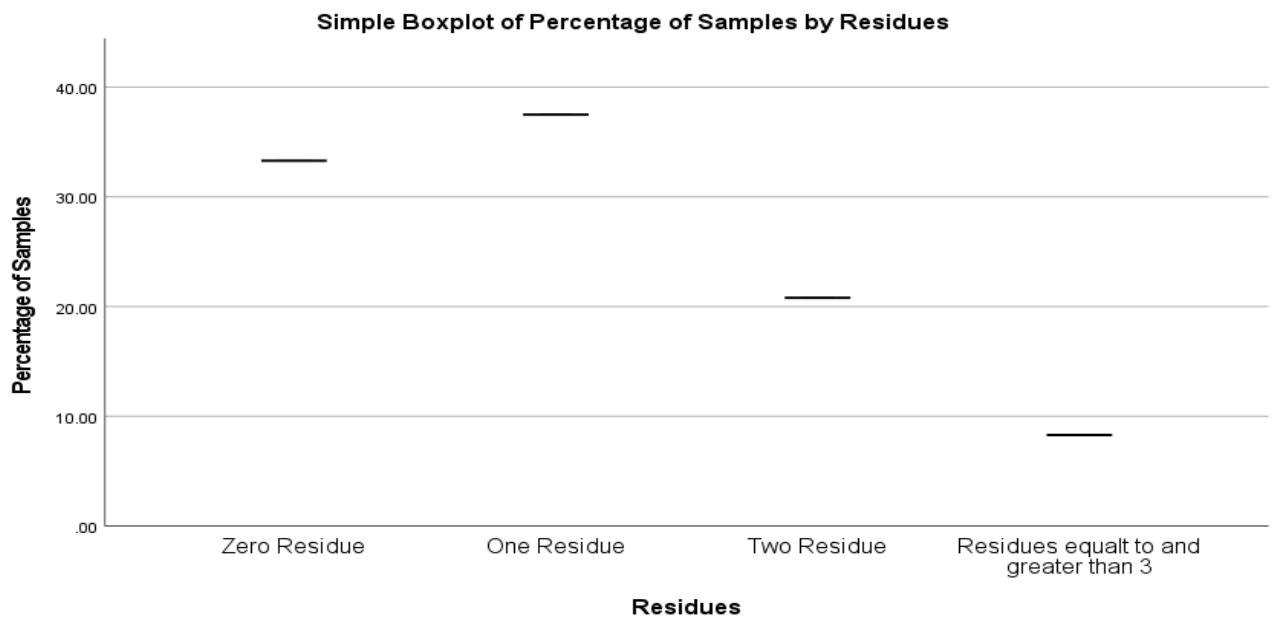

Figure 2 Co-occurrences of pesticides residues in samples

\subsection{Translocation study}

The translocation ability of a plant is the ability to transfer its pesticides or chemicals to different parts such as the surface, peel, and pulp (Wang et al. 2011). Penetration factor (PF) is calculated as the ratio of pesticide concentration in the peel to the pulp. This factor can be used to study peel to pulp translocation and is calculated as the ratio of surface concentration to peel concentration to determine the translocation of pesticides from surface to peel (Lozowicka et al. 2020); the higher the PF values, the better is the translocation between the skin and pulp.

$$
\begin{gathered}
\text { PF for surface to peel }=C_{\text {surface }} / C_{\text {peel }} \\
\text { PF for peel to pulp }=C_{\text {peel }} / C_{\text {pulp }}
\end{gathered}
$$

For the apple samples, the PF of surface to peel $\left(\mathrm{C}_{\text {surface }} / \mathrm{C}_{\text {peel }}\right)$ and that of peel to pulp $\left(\mathrm{C}_{\text {peee }} / \mathrm{C}_{\text {pulp }}\right)$ ranged from 0.02 to 5.28 and 0.0 to 189.16, respectively. The highest $\mathrm{PF}$ of surface to peel $\left(\mathrm{C}_{\text {surface }} / \mathrm{C}_{\text {peel }}\right)$ was observed for beta endosulfan (average value, 4.91). In the case of $\mathrm{C}_{\text {peee }} / \mathrm{C}_{\text {pulp }}$, higher PF (118.63) was observed for malathion, followed by carbaryl (48.07) and chlorpyrifos. Higher PF value of malathion and carbaryl indicated that the maximum pesticide concentration penetrated and moved to the pulp after $24 \mathrm{~h}$. High PF values indicate better translocation between the skin and pulp.

For the tomato samples, PF ranged from 4.29 to 16.95 . Higher PF was observed for flubendiamide (average value, 14.22), followed by thiomethoxam (average value, 7.49). For the brinjal samples, the average PF of 37.34 was observed for flubendiamide (Figure 3, 4 , and 5). 


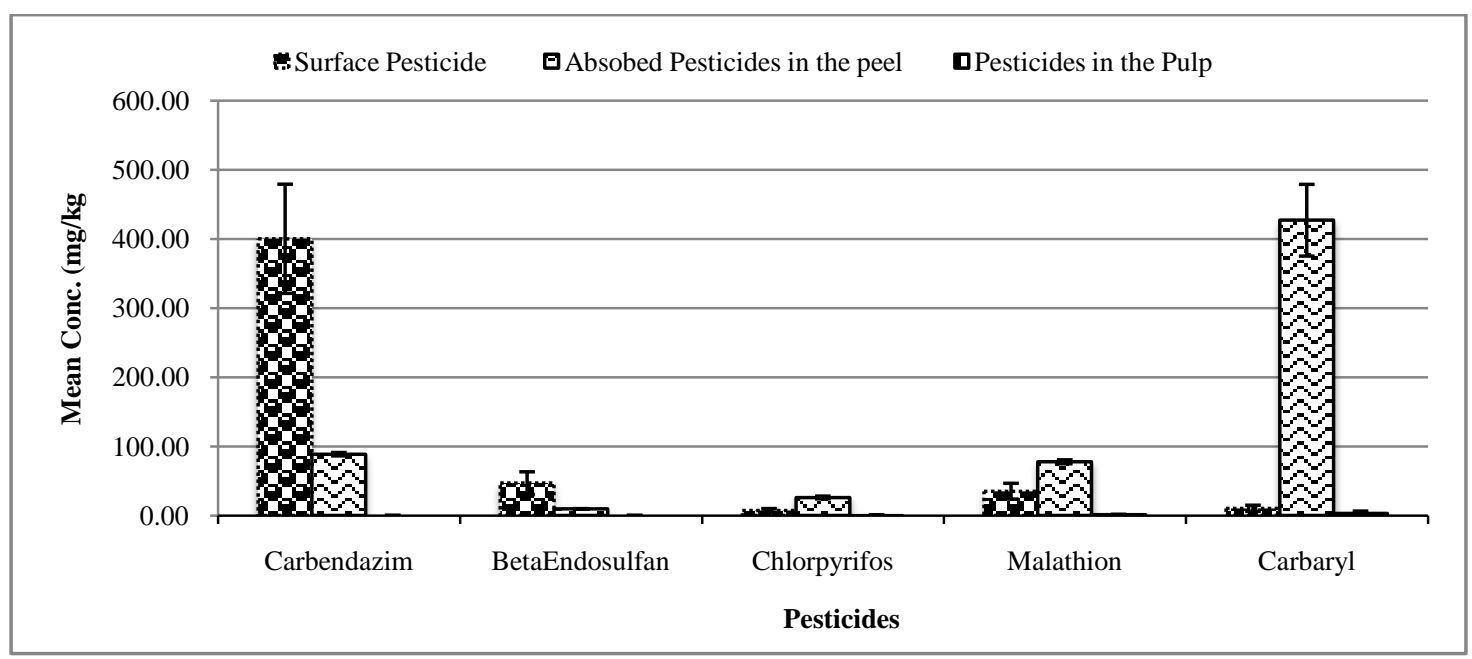

Figure 3 Translocation of pesticides residues in apples

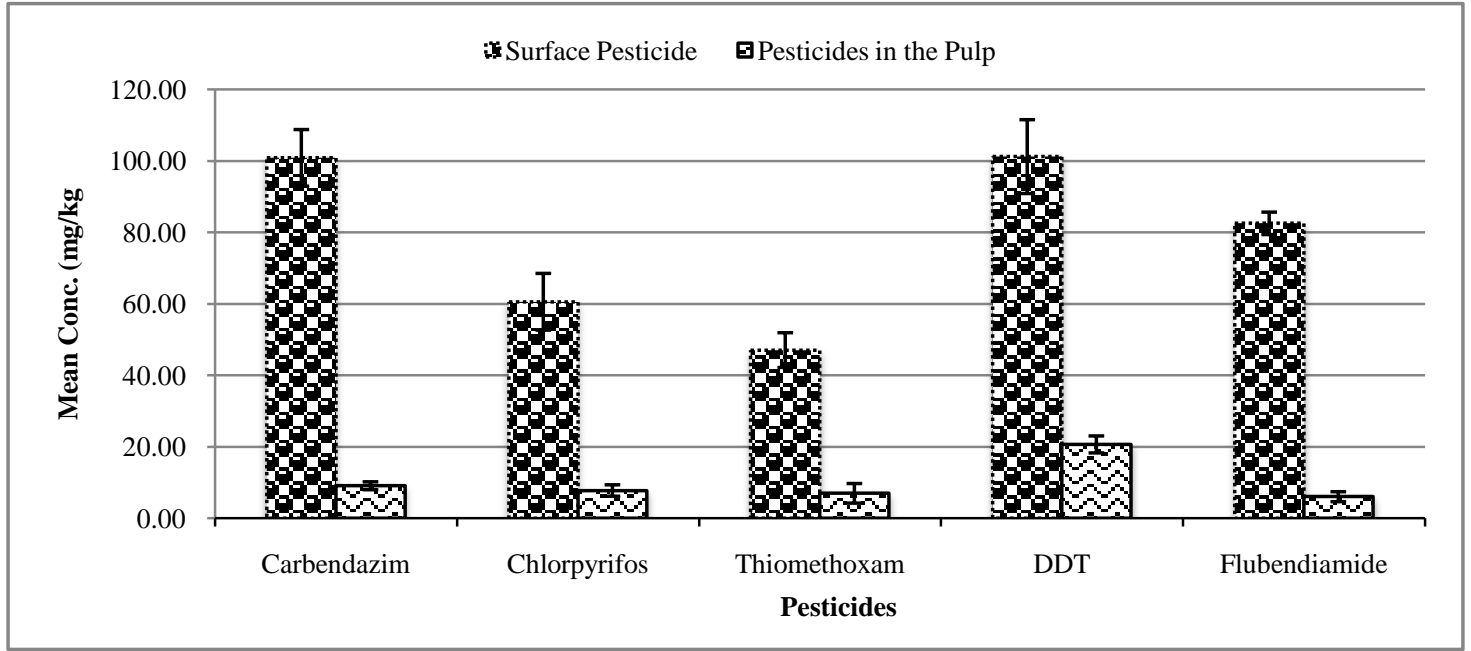

Figure 4 Translocation of pesticides residues in tomatoes

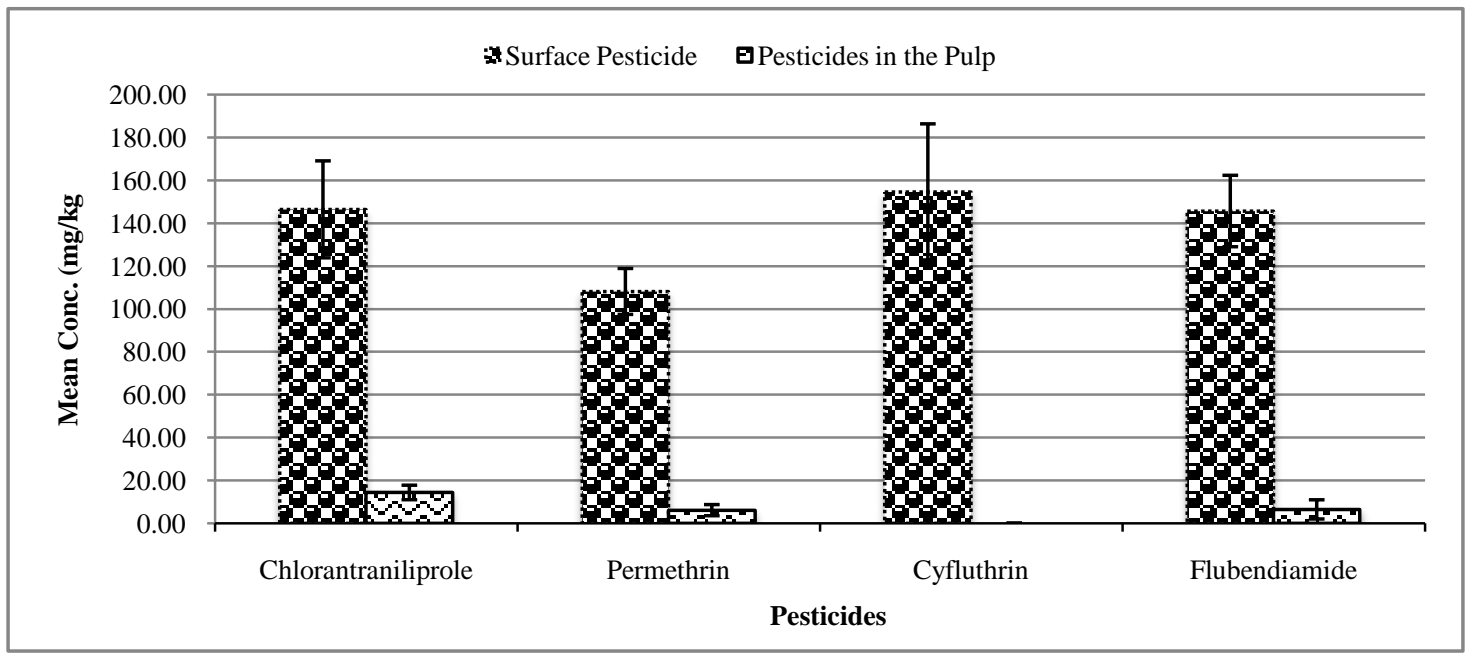

Figure 5 Translocation of pesticides residues in brinjal

Journal of Experimental Biology and Agricultural Sciences http://www.jebas.org 
Table 6 Reduction in pesticides residues after washing treatment

\begin{tabular}{|c|c|c|c|c|}
\hline Pesticides name & $\begin{array}{l}\% \text { Reduction } \\
\text { water }\end{array}$ & $\begin{array}{l}\% \text { Reduction in } 0.1 \% \\
\text { Sodium Carbonate }\end{array}$ & $\begin{array}{l}\% \text { Reduction in } 0.1 \% \text { mixtue of absorbic } \\
\text { acid and sodium carbonate }(70: 30 \mathrm{v} / \mathrm{v})\end{array}$ & $\begin{array}{l}\text { \% Reduction in } 0.1 \\
\% \text { Ascorbic Acid }\end{array}$ \\
\hline \multicolumn{5}{|c|}{ Apples } \\
\hline Carbendazim (MBC) & 88.16 & 91.80 & 96.05 & 66.10 \\
\hline BetaEndosulfan & 83.96 & 82.08 & 83.75 & 65.52 \\
\hline Chlorpyrifos & 87.52 & 88.97 & 86.91 & 61.74 \\
\hline malathion & 97.12 & 97.83 & 97.93 & 21.67 \\
\hline carbaryl & 96.43 & 97.14 & 97.42 & 39.77 \\
\hline \multicolumn{5}{|c|}{ Tomatoes } \\
\hline Carbendazim (MBC) & 93.94 & 93.17 & 95.12 & 69.31 \\
\hline Chlorpyrifos & 90.58 & 90.88 & 94.85 & 70.85 \\
\hline Thiomethoxam & 98.06 & 71.54 & 98.06 & 87.80 \\
\hline DDT & 55.03 & 64.35 & 66.53 & 66.53 \\
\hline Flubendiamide & 64.51 & 63.76 & 87.76 & 48.47 \\
\hline \multicolumn{5}{|c|}{ Brinjal } \\
\hline Chlorantraniliprole & 77.99 & 90.86 & 93.74 & 31.21 \\
\hline Permethrin & 59.76 & 91.73 & 88.64 & 64.82 \\
\hline Cyfluthrin & 97.09 & 96.61 & 97.70 & 82.73 \\
\hline Flubendiamide & 58.63 & 83.38 & 71.74 & 58.45 \\
\hline
\end{tabular}

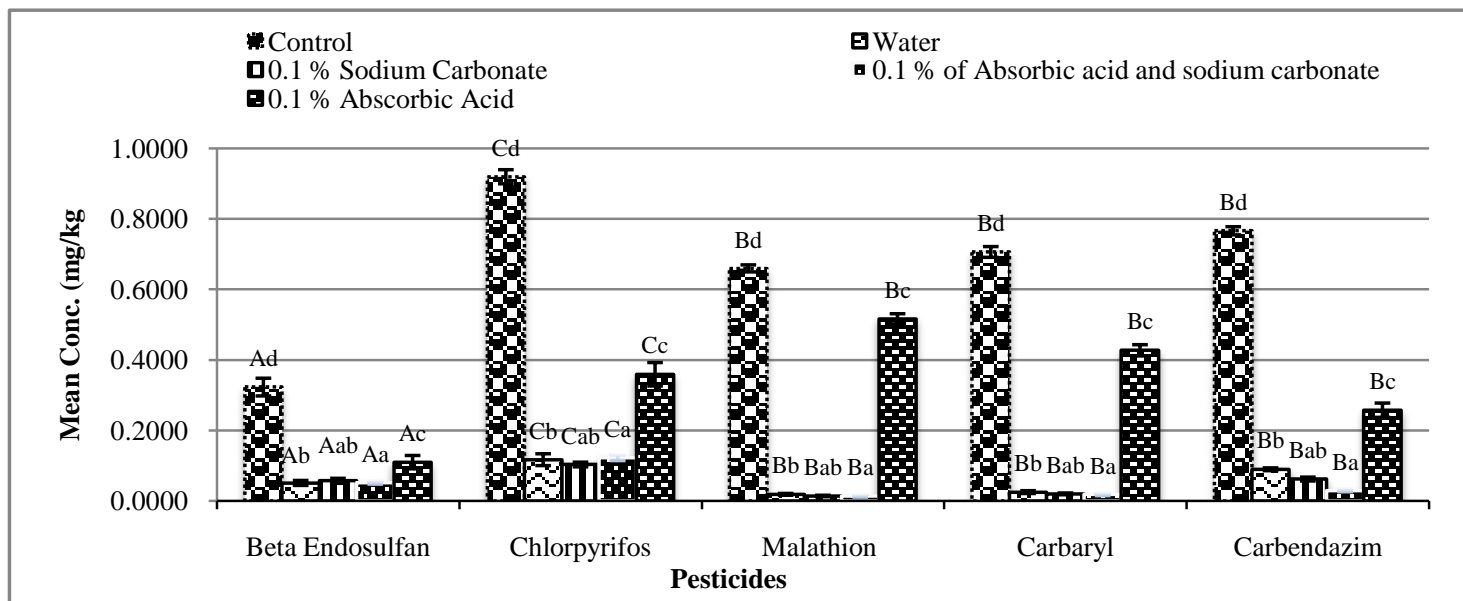

Figure 6 Different washing solutions effectiveness on removal of different pesticides in apples. All the values are mean of triplicates \pm S.D. ANOVA significant at $\mathrm{p}<0.05$. Different capital letters indicate significant difference when compared between different pesticides and small letters indicate significantly different values when compared between different treatments (DMRT, $\mathrm{p}<0.05$ ).

\subsection{Pesticide reduction study}

Table 6 presents the data for the percentage reduction of pesticides in the apple, tomato, and brinjal samples. To determine the percentages of pesticide reduction, the samples were spiked with a pesticide mix solution and washed after $24 \mathrm{~h}$ with $0.1 \%$ ascorbic acid; $0.1 \%$ sodium carbonate; and a mix solution of ascorbic acid and sodium carbonate in a ratio of $50: 50 \mathrm{v} / \mathrm{v}$ and water. The concentration after washing treatment was compared with the concentration obtained from untreated samples. In the untreated apple samples, the total concentrations of carbendazim, beta endosulfan, chlorprifos, malathion, and carbaryl in apple were $0.76,0.32,0.94,0.66$, and $0.71 \mathrm{ppm}$, respectively. In tomato samples, the concentrations of carbendazim, chlorpyrifos, thiomethoxam, DDT, and flubendiamide were $0.82,1.1,0.91,0.49$, and 0.85 , respectively, whereas, in brinjal samples, the concentrations for chlorantraniliprole, permethrin, cyfluthrin, and flubendiamide were $0.58,1.23,0.55$, and $0.73 \mathrm{ppm}$, respectively (Figure 6, 7, and 8). 


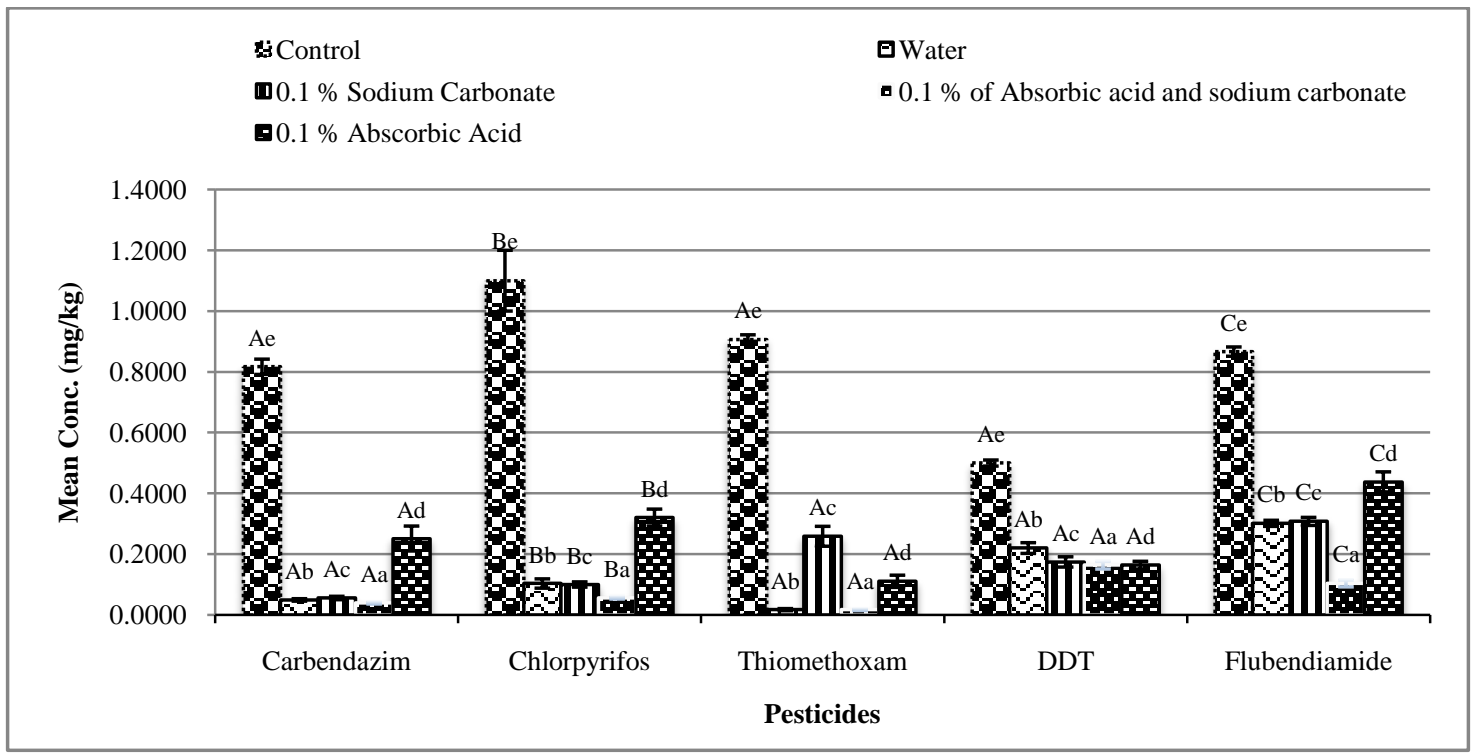

Figure 7 Different washing solutions effectiveness on removal of different pesticides in tomatoes. All the values are mean of triplicates \pm S.D. ANOVA significant at $\mathrm{p}<0.05$. Different capital letters indicate significant difference when compared between different pesticides and small letters indicate significantly different values when compared between different treatments (DMRT, $\mathrm{p}<0.05$ ).

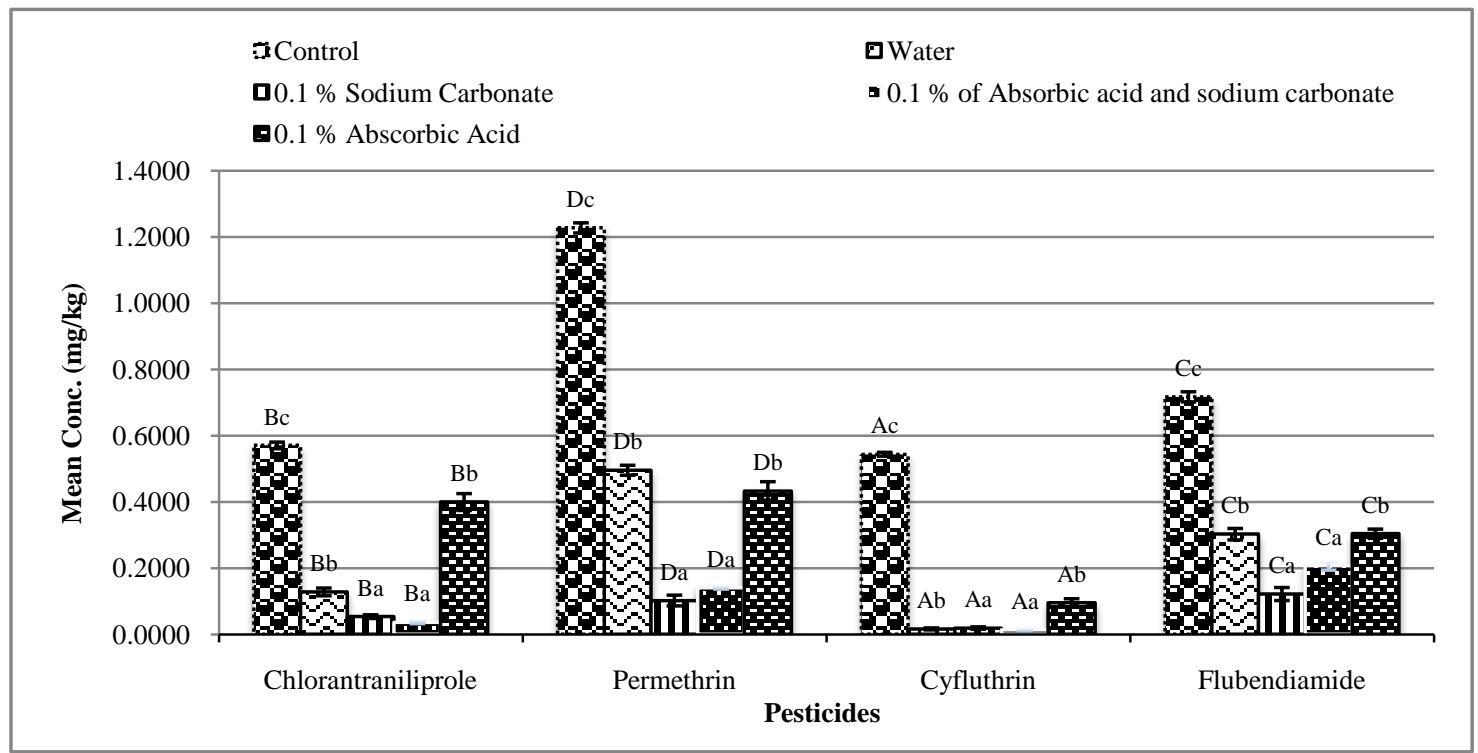

Figure 8 Different washing solutions effectiveness on removal of different pesticides in brinjal. All the values are mean of triplicates \pm S.D.

ANOVA significant at $\mathrm{p}<0.05$. Different capital letters indicate significant difference when compared between different pesticides and small letters indicate significantly different values when compared between different treatments (DMRT, $\mathrm{p}<0.05$ ).

In the apple samples, malathion percentage reduction ranged from 21.67 to $97.93 \%$ and was more in the mixed solution, this was followed by the combination of sodium carbonate, water, and ascorbic acid which exhibited $21 \%$ reduction in malathion. Similarly, the carbaryl percentage reduction ranged from 39.77 to $97.42 \%$, and the highest reduction was reported in mixed solution while the lowest reduction was observed in ascorbic acid solution. Mixed solution and washing treatment with water results were comparable in apples. In tomatoes, a higher reduction was observed in thiomethoxam (71.54-98.06\%), carbendazim (69.31 $95.12 \%)$, and chlorpyrifos $(70.84-94.85 \%)$, whereas less reduction was observed in DDT $(55.03 \%-66.53 \%)$. The mixed solution reduction results were superior in tomatoes. In brinjal, a high reduction was observed in cyfluthrin, followed by chlorantraniliprole. However, a low reduction was observed in flubendiamide. 
Pesticide reduction in water ranged from 55.03 to $98.06 \%$. In the present study, the residue reduction was not directly correlated to pesticide solubility in water. The water solubility of thiomethoxam, malathion, and chlorpyrifos was highest among all the pesticides. The percentage reduction of thiomethoxam was $87.80 \%$ in tomatoes, malathion residue reduction was $21.67 \%$ in apples, chlorpyrifos residues reduction was $61.74 \%$ in apples, and $70.85 \%$ in tomatoes (Figure 6, 7, and 8).

\section{Discussions}

Chlorpyrifos levels in tomatoes were higher than the MRL in the present study. Similarly, higher chlorpyrifos concentrations in tomato was reported by Elgueta et al. (2017). The presence of chlorpyrifos in vegetables is consistent with the study by Kunyanga et al. (2018). Chlorpyrifos is a widely used insecticide that is highly efficient against various pests (Amoah et al. 2006; Angioni et al. 2011; Omwenga et al. 2021). It is also registered for use in fruits and vegetables in India as per FSSAI (Food Safety Regulation of India). Chlorpyrifos is persistent in nature, can be magnified, and bioaccumulates in plants. The World Health Organization, Food and Agricultural Organization, and US Environmental Protection Agency have classified chlorpyrifos to be moderately or highly hazardous to human health (WHO Programme on chemical safety 2009; Roberts \& Reigart 2013; Omwenga et al. 2021). In the present study, the presence of DDT (banned agrochemicals) was also detected from the tomatoes. This finding is concurrent with that of Dari et al. (2016). Pesticides organophosphates and carbamates are safer than organochlorines such as DDT, aldrin, and dieldrin (Fernandez et al. 2000) Although DDT is banned, it is still available in the market in the unlabeled form and packaging material. Uneducated farmers are unaware that DDT has been prohibited. Further agricultural chemicals that are not intended for apple and tomato production are utilized in their production, which is an alarming situation that necessitates the investigation on how these pesticides reached the market (Dari et al. 2016). Lipid content, rate of rainfall, soil properties, soil organisms, and temperature affects the occurrences of pesticides in different food matrices (Bento et al. 2016). Multiple residues might be the consequence of persistent insecticides being absorbed by plants (Zhang et al. 2017) and poor agricultural practices of using more than one pesticide during application (Omwenga et al. 2021). Jallow et al. (2017) exhibited multiple residues resulting from different pesticide applications. Because of the low perception of pesticide toxicity and the strong demand for the crop, growers sometimes do not wait for residues to wash off before harvesting (Agyekum et al. 2015).

Several herbicides, as well as the majority of organophosphate and organochlorine insecticides and some carbamate insecticides, translocate into plants at non-lethal concentrations (Edwards
1975). Pesticides have a variety of chemical characteristics and modes of action including absorption, adsorption, and elimination (Agyekum et al. 2015; Li et al. 2019; Lozowicka et al. 2020). Pesticide absorption and movement in plant tissues are ascertained by physical and chemical properties. Further, some translaminar pesticides only move a short distance from the surface into the tissues, although some non-systemic pesticides do not penetrate into the plant tissues or only penetrate in a small amount (Hou et al. 2016; Lozowicka et al. 2020). Some organic compounds may volatilize from the soil and penetrate into the plant leaves through the cuticle or stomata (Collins et al. 2006). Different penetration abilities may be due to differences in the cuticle and epicuticular wax and dust on the fruit surface. These waxes and cuticles make a non-uniform surface which acts as a barrier for pesticides (Yang et al. 2016; Kvesitadze et al. 2015). Yang et al. (2016) reported that systemic pesticides can penetrate faster and deeper into fresh produce. However, the present study exhibited that although the systemic pesticide moved faster from the surface to peel and accumulated there, but these could not penetrate much into the pulp as compared to the non-systemic pesticides. Systemic pesticides such as carbendazim translocated from surface to peel. This finding is concurrent with that of Yang et al. (2016). Lozowickaa et al. (2020) reported that chlorpyrifos is one of the main compounds found in the apple peel. In the present study, chlorpyrifos translocated from the surface to peel and from peel to pulp much faster than other pesticides. Similarly, Łozowickaa et al. (2020) reported the highest concentrations of non-systemic acaricide, Carbaryl, insecticides, and chlorpyrifos from the apple peel. Differences may be observed in the adjuvant used in commercial pesticide formulations, and this is based on the lipophilic nature of the pesticide, the concentration of pesticides employed, application duration, and sampling (Finizio et al., 1997). In the whole apple, high levels of non-systemic acaricide such as beta endosulfan and non-systemic carbamates such as carbaryl may be attributed to the presence of micro-fissures in the skin due to abiotic or pest damage in an apple during the maturation stage, allowing entry into the peel (Lozowicka et al. 2020). Agyekum et al. (2015) exhibited dieldrin, fenitrothion, chlorpyrifos, lindane, and DDT in the peel of tomatoes. The peel retained higher organophosphorus and organochlorine pesticides than the other fractions. In the present study, chlorpyrifos and DDT concentrations in the tomato peels were high and these findings are supported by the findings of Agyekum et al. (2015). The concentration of organochlorine pesticides in the current study was similar to that reported by Mbakaya \& Ngowi (1994). The present study results are concurrent with the findings of Kumari et al. (2002; 2003) and Deka et al. (2005).

As per the solubility of pesticides, the thiomethoxam concentration reduction was high while malathion reduction was less as per its solubility, which may be due to the presence of wax and dust on 
the apple surface. Pesticide removal efficacy will depend on the fruit surface. Thus, no correlation was observed between pesticide solubility in water and pesticide reduction after washing. These findings are consistent with those of other studies (Satpathy et al. 2012; Youssef et al. 1995; Izumi 1999). Percentage reduction in ascorbic acid was less in the case of all applied pesticides except DDT. Thus, the mixture of ascorbic acid and sodium carbonate was selected. For removal of the pesticides residues, $0.1 \%$ mixture of ascorbic acid and sodium carbonate $(70: 30 \mathrm{v} / \mathrm{v})$ was found to be effective. Additionally, $94.85 \%$ of chlorpyrifos, which is found in vegetables, can be removed using this washing solution. The movement of chemicals from one part of a plant to another also depends on the physiochemical properties of the chemical (Pullagurala et al. 2018; Zhang et al. 2017).

In the present study, the solution of sodium carbonate and ascorbic acid was observed to be more effective than water in removing pesticide residues. Alessandra exhibited that pesticides residue removal by sodium bicarbonate was more efficient than water (Rodrigues et al. 2017). These findings are concurrent with that of the present study. Rasolonjatovo et al. (2017) also concluded that a blend of washing solution is more effective than a single solution in removing pesticide residues as it exhibits a synergetic effect, which is in agreement with the findings of the present study. YuShan et al. (2013) confirmed that mixing sodium bicarbonate with water forms carbonic acid, can remove pesticides through oxidation. Polat \& Tiryaki (2020) confirmed that acetic acid and citric acid washing treatments were more efficient than tap water treatment. Additionally, Holland et al. (1994) exhibited that water solubility was the most significant parameter for pesticide residue. Although highly soluble pesticides can be easily removed from agricultural commodities (Randhawa et al. 2014; Holland et al. 1994; Lozowicka et al. 2020). Water alone was not found effective in the removal of pesticide residues. As per FSSAI Guidance Note 13/2020, pesticide residues in fruits and vegetables were reduced using methods such as scrubbing with a soft brush. According to the FSSAI guidance, washing with water removes $75 \%-80 \%$ of pesticide residues from the surface of fruits and vegetables, which supports the current study findings. However, a chemically prepared solution was better and more effective than water alone and a single washing solution because the chemicals present in mixed solutions work in synergy by interacting with each other.

\section{Conclusions}

The presence of pesticides on fruits and vegetable samples collected from the Ghaziabad district underlines the requirement to educate farmers on the usage and dosage of pesticide residues. A checklist of approved and banned chemicals to the food commodity should be supplied to the farmers. Agrochemical assistance must be provided to farmers for the selection of agrochemicals and their application at the right time and quantity. Furthermore, proper and frequent monitoring of pesticides available in local fruit and vegetable markets is required. Penetration behavior of pesticides was observed on the surface, pulp, and peel of fruits and vegetables. Physiochemical properties affect pesticide adsorption, absorption, and penetration. Additionally, some systemic pesticides penetrate deeply. This study will facilitate the design of guidelines for the safe application of pesticides to apple, tomato, and brinjal plants. Furthermore, a study of the effect of washing solutions exhibited that the solution of ascorbic acid: sodium carbonate $(30: 70 \mathrm{v} / \mathrm{v})$ is more effective in reducing the pesticide residues from fruits and vegetables than water and single chemical alone. Pesticide reduction along with the physicochemical properties of pesticides also depend on the active components of the chemical that interact with each other and effectively reduce the pesticide level. Thus pesticide residues can be reduced from fruits and vegetables using a mixture of chemical washing solution and peel removal.

\section{Acknowledgments}

The authors are thankful to the Amity Institute of environmental sciences, Noida to conduct the research successfully. We acknowledge our sincere thanks to all those from AIES who extended their kind help and support.

\section{Conflict of interests}

The authors hereby declare no conflict of interest.

\section{Funding}

The authors did not received funding support from any organization for the submitted work.

\section{Ethical issues}

There are no ethical issues to declare.

\section{Data availability}

The data that support the findings of this study are available from the corresponding author upon reasonable request.

\section{References}

Abolhassani, M., Asadikaram, G., Paydar, P., Fallah, H., et al. (2019). Organochlorine and organophosphorous pesticides may induce colorectal cancer, Acase-control study. Ecotoxicology and environmental safety, 178, 168-177. DOI: 10.1016/j.ecoenv.2019.04.030.

Abou-Arab, A. A. K. (1999). Behavior of pesticides in tomatoes during commercial and home preparation. Food chemistry, 65(4), 509-514. 
Agyekum, A. A., Ayernor, G. S., Saalia, F. K., \& Bediako-Amoa, B. (2015). Translocation of pesticide residues in tomato, mango and pineapple fruits. Journal of Food Science and Engineering, 5, 142-149. DOI: 10.17265/2159-5828/2015.02.006.

Akoto, O., Gavor, S., Appah, M. K., \& Apau, J. (2015). Estimation of human health risk associated with the consumption of pesticidecontaminated vegetables from Kumasi, Ghana. Environmental Monitoring and Assessment, 187(5), 1-9. DOI: 10.1007/s10661015-4471-0.

Amoah, P., Drechsel, P., Abaidoo, R. C., \& Ntow, W. J. (2006) Pesticide and pathogen contamination of vegetables in Ghana's urban markets. Archives of Environmental Contamination and Toxicology, 50(1), 1-6. DOI: 10.1007/s00244-004-0054-8.

Angioni, A., Dedola, F., Garau, A., Sarais, G., Cabras, P., \& Caboni, P. (2011). Chlorpyrifos residues levels in fruits and vegetables after field treatment. Journal of Environmental Science and Health, Part B, 46(6), 544-549. DOI 10.1080/03601234.2011.583880.

Bento, C. P., Yang, X., Gort, G., Xue, S., et al. (2016). Persistence of glyphosate and aminomethylphosphonic acid in loess soil under different combinations of temperature, soil moisture and light/darkness. Science of the Total Environment, 572, 301311.DOI: 10.1016/j.scitotenv.2016.07.215.

BS EN 15662 (2018) Foods of plant origin multi method for the determination of pesticide residues using GC- and LC-based analysis following acetonitrile extraction/partitioning and clean-up by dispersive SPE, modular QuEChERS-method.

Centers for Disease Control and Prevention Report (2019). Fourth national report on human exposure to environmental chemicals. Atlanta (GA): National Center for Environmental Health. Retrieve from https://www.cdc.gov/exposurereport/pdf/FourthReport UpdatedTables_Volume1_Jan2019-508.pdf.

Collins, C., Fryer, M., \& Grosso, A. (2006). Plant uptake of nonionic organic chemicals. Environmental Science \& Technology, 40(1), 45-52.DOI: 10.1021/es0508166.

Dari, L., Addo, A., \& Dzisi, K. A. (2016). Pesticide use in the production of tomato (Solanum lycopersicum L.) in some areas of Northern Ghana. African Journal of Agricultural Research, 11(5), 352-355. DOI: 10.5897/AJAR2015.10325.

Deka, S. C., Barman, N., \& Baruah, A. A. L. H. (2005). Pesticidal contamination status in farmgate vegetables in Assam, India. Pesticide Research Journal, 17(2), 90-93. DOI 10.1023/a:1014248827898.
Edwards, C. A. (1975). Factors that affect the persistence of pesticides in plants and soils. In Pesticide Chemistry-3, Third International Congress of Pesticide Chemistry Including the Symposium on Dispersion Dynamics of Pollutants in the Environment (pp. 39-56). Butterworth-Heinemann.

Elgueta, S., Moyano, S., Sepúlveda, P., Quiroz, C., \& Correa, A. (2017). Pesticide residues in leafy vegetables and human health risk assessment in North Central agricultural areas of Chile. Food Additives \& Contaminants: Part B, 10(2), 105-112. DOI: 10.1080/19393210.2017.1280540.

Fan, L., Niu, H., Yang, X., Qin, W., et al. (2015). Factors affecting farmers' behaviour in pesticide use: Insights from a field study in northern China. Science of the Total Environment, 537, 360-368. DOI: $10.1016 / j . s c i t o t e n v .2015 .07 .150$.

Felizeter, S., McLachlan, M. S., \& De Voogt, P. (2012). Uptake of perfluorinated alkyl acids by hydroponically grown lettuce (Lactuca sativa). Environmental science \& technology, 46(21), 11735-11743. DOI: 10.1021/es302398u.

Fernández, M., Picó, Y., \& Manes, J. (2000). Determination of carbamate residues in fruits and vegetables by matrix solid-phase dispersion and liquid chromatography-mass spectrometry. Journal of Chromatography A,871(1-2), 43-56. DOI: S00219673(99)00907-3.

Finizio, A., Vighi, M., \& Sandroni, D. (1997). Determination of noctanol/water partition coefficient (Kow) of pesticide critical review and comparison of methods. Chemosphere, 34(1), 131-161. DOI: 10.1016/S0045-6535(96)00355-4.

FSSAI Guidance Note No. 13/2020 (2020).Pesticides: Food safety concerns, precautions and safety measures.

Haines, D. A., Saravanabhavan, G., Werry, K., \& Khoury, C. (2017). An overview of human biomonitoring of environmental chemicals in the Canadian Health Measures Survey: 20072019. International Journal of hygiene and environmental health, 220(2), 13-28.DOI: 10.1016/j.ijheh.2016.08.002.

Holland, P. T., Hamilton, D., Ohlin, B., \& Skidmore, M. W. (1994). Effects of storage and processing on pesticide residues in plant products. Pure and applied chemistry, 66(2), 335-356.

Hou, R., Zhang, Z., Pang, S., Yang, T., Clark, J. M., \& He, L. (2016). Alteration of the nonsystemic behavior of the pesticide ferbam on tea leaves by engineered gold nanoparticles. Environmental Science \& Technology,50(12), 6216-6223. DOI: 10.1021/acs.est.6b01336

https://doi.org/10.1016/j.watres.2018.12.039 
Izumi, H. (1999). Electrolyzed water as a disinfectant for fresh-cut vegetables. Journal of Food Science, 64(3), 536539.DOI:10.1111/j.1365-2621.1999.tb15079.

Jallow, M. F., Awadh, D. G., Albaho, M. S., Devi, V. Y., \& Ahmad, N. (2017). Monitoring of pesticide residues in commonly used fruits and vegetables in Kuwait. International Journal of environmental research and public health, 14(8), 833..DOI:10.3390/ijerph14080833.

Jardim, A. N. O., Brito, A. P., van Donkersgoed, G., Boon, P. E., \& Caldas, E. D. (2018). Dietary cumulative acute risk assessment of organophosphorus, carbamates and pyrethroids insecticides for the Brazilian population. Food and chemical toxicology, 112, 108117.DOI: 10.1016/j.fct.2017.12.010.

Kaushik, G., Satya, S., \& Naik, S. N. (2009). Food processing a tool to pesticide residue dissipation-Areview. Food Research International, 42 (1), 26-40. DOI:10.1016/j.foodres.2008.09.009.

Klinhom, P., Halee, A., \& Methawiwat, S. (2008). The effectiveness of household chemicals in residue removal of methomyl and carbaryl pesticides on Chinese-kale. Agriculture and Natural Resources, 42(5), 136-143.

Krol, W. J., Arsenault, T. L., Pylypiw, H. M., \& Incorvia Mattina, M. J. (2000). Reduction of pesticide residues on produce by rinsing. Journal of Agricultural and Food chemistry, 48(10), 46664670. DOI: 10.1021/jf0002894.

Kumari, B., Kumar, R., Madan, V. K., Singh, R., Singh, J., \& Kathpal, T. S. (2003). Magnitude of pesticidal contamination in winter vegetables from Hisar, Haryana. Environmental Monitoring and Assessment, 87(3), 311-318. DOI:10.1023/A:1024869505573.

Kumari, B., Madan, V. K., Kumar, R., \& Kathpal, T. S. (2002). Monitoring of seasonal vegetables for pesticide residues. Environmental Monitoring and Assessment, 74(3), 263 270.

Kunyanga, C., Amimo, J., Kingori, L. N., \& Chemining'wa, G. (2018). Consumer risk exposure to chemical and microbial hazards through consumption of fruits and vegetables in Kenya. Food Sci Qual Manage, 78, 2225-0557.

Kvesitadze, G., Khatisashvili, G., Sadunishvili, T., \& Kvesitadze, E. (2015). Plants for remediation: Uptake, translocation and transformation of organic pollutants. In Öztürk M., Ashraf M., Aksoy A., Ahmad M., \& Hakeem K. (eds) Plants, pollutants and remediation (pp. 241-308). Springer, Dordrecht. DOI :10.1007/978-94-017-7194-8_12.
Li, Y., Sallach, J. B., Zhang, W., Boyd, S. A., \& Li, H. (2019). Insight into the distribution of pharmaceuticals in soil-water-plant systems. Water research, 152, 38-46. DOI:

Łozowicka, B., Kaczyński, P., Mojsak, P., Rusiłowska, J., et al. (2020). Systemic and non-systemic pesticides in apples from Kazakhstan and their impact on human health. Journal of Food Composition and Analysis, 90, 103494.DOI: 10.1016/j.jfca.2020.103494.

Mbakaya, C., \& Ngowi, A. V. (1994). The status of pesticide usage in East Africa. African Journal of Health Sciences, 1(1), 37-41

Nguyen, T. T., Rosello, C., Bélanger, R., \& Ratti, C. (2020). Fate of residual pesticides in fruit and vegetable waste (FVW) processing. Foods, 9(10),1468. DOI:10.3390/foods9101468.

Omwenga, I., Kanja, L., Zomer, P., Louisse, J., Rietjens, I. M., \& Mol, H. (2021). Organophosphate and carbamate pesticide residues and accompanying risks in commonly consumed vegetables in Kenya. Food Additives \& Contaminants: Part B, 14(1), 48-58. DOI: $10.1080 / 19393210.2020 .1861661$.

Polat, B., \& Tiryaki, O. (2020). Assessing washing methods for reduction of pesticide residues in Capia pepper with LCMS/MS. Journal of Environmental Science and Health, Part B, 55(1), 1-10. DOI: 10.1080/03601234.2019.1660563.

Pullagurala, V. L. R., Rawat, S., Adisa, I. O., Hernandez-Viezcas, J. A., Peralta-Videa, J. R., \& Gardea-Torresdey, J. L. (2018). Plant uptake and translocation of contaminants of emerging concern in soil. Science of the Total Environment, 636, 1585-1596. DOI: 10.1016/j.scitotenv.2018.04.375.

Randhawa, M. A., Anjum, M. N., Butt, M. S., Yasin, M., \& Imran, M. (2014). Minimization of imidacloprid residues in cucumber and bell pepper through washing with citric acid and acetic acid solutions and their dietary intake assessment. International Journal of Food Properties, 17(5), 978-986. DOI:10.1080/10942912.2012.678532.

Rasolonjatovo, M. A., Cemek, M., Cengiz, M. F., Ortaç, D., et al. (2017). Reduction of methomyl and acetamiprid residues from tomatoes after various household washing solutions. International Journal of Food Properties,20(11), 2748-2759. DOI: 10.1080/10942912.2016.1250099.

Roberts, J. R., \& Reigart, J. R. (2013). Recognition and management of pesticide poisonings. Retrieve from http://www2.epa.gov/pesticide-worker-safety.

Rodrigues, A. A., De Queiroz, M. E. L., De Oliveira, A. F., Neves, A. A., et al. (2017). Pesticide residue removal in classic domestic 
Environmental Science and Health, part b,52(12), 850-857. DOI:10.1080/03601234.2017.1359049.

SANTE Guideline, SANTE/12682/2019 (2020). Analytical quality control and method validation procedures for pesticide residues analysis in food and feed. Retrieved from https://www.eurlpesticides.eu/userfiles/file/EurlALL/AqcGuidance_SANTE_2019_ 12682.pdf .

Satpathy, G., Tyagi, Y. K., \& Gupta, R. K. (2012). Removal of organophosphorus (OP) pesticide residues from vegetables using washing solutions and boiling. Journal of Agricultural Science, 4(2), 69-78.DOI:10.5539/jas.v4n2p69.

Subash, S. P., Chand, P., Pavithra, S., Balaji, S. J., \& Pal, S. (2018). Pesticide use in Indian agriculture: trends, market structure and policy issues. Policy Brief retrieved from file:///C:/Users/user/Downloads/PolicyBrief4thProof_final2018_01 _17.pdf.

Wang, S., Zhang, S., Huang, H., Zhao, M., \& Lv, J. (2011). Uptake, translocation and metabolism of polybrominated diphenyl ethers (PBDEs) and polychlorinated biphenyls (PCBs) in maize (Zea mays L.). Chemosphere, 85(3), 379-385. DOI:10.1016/j.chemosphere.2011.07.002

Wang, W., Wan, Q., Li, Y., Xu, W., \& Yu, X. (2019). Uptake, translocation and subcellular distribution of pesticides in Chinese cabbage (Brassica rapa var. chinensis). Ecotoxicology and 10.1016/j.ecoenv.2019.109488.

World Health Organization International Programme on Chemical Safety. (2009). The WHO recommended classification of pesticides by hazard and guidelines to classification. Retrieved from https://apps.who.int/iris/bitstream/handle/10665/44271/978924154796 3_eng.pdf.

Yang, T., Zhao, B., Hou, R., Zhang, Z., et al. (2016). Evaluation of the penetration of multiple classes of pesticides in fresh produce using surface-enhanced Raman scattering mapping. Journal of Food Science, 81(11), T2891-T2901.DOI: 10.1111/17503841.13520 .

Youssef, M. M., El-all, A. A., Radwan, M. A., El-Henawy, G. L., \& Marei, A. S. (1995). Removal of Pirimiphos-Methyl and Chlorpyrifosmethyl Residues from Treated Tomatoes and Broad Beans by Commercial and Home Preparative Procedures. Alexandria Science Exchange, 16, 461-470.

Yu-shan, Z. H. A. N. G., Xiao-peng, L. I., Hong-mei, L. I. U., Yao-kun, Z. H. A. N. G., et al. (2013). Study on universal cleaning solution in removing blended pesticide residues in Chinese cabbage. Journal of Environmental Chemistry and Ecotoxicology, 5(8), 202-207.DOI: 10.5897/JECE2013.0288.

Zhang, C., Yao, F. E. N. G., Liu, Y. W., Chang, H. Q., Li, Z. J., \& Xue, J. M. (2017). Uptake and translocation of organic pollutants in plants: A review. Journal of Integrative Agriculture, 16(8), 1659-1668.DOI: 10.1016/S2095-3119(16)61590-3. 